\title{
Understanding Others' Feelings: The Role of the Right Primary Somatosensory Cortex in Encoding the Affective Valence of Others' Touch
}

\author{
Nadia Bolognini, ${ }^{1,2}$ Angela Rossetti, ${ }^{1}$ Silvia Convento, ${ }^{1}$ and Giuseppe Vallar ${ }^{1,2}$ \\ ${ }^{1}$ Department of Psychology, University of Milano Bicocca, 20126 Milano, Italy, and ${ }^{2}$ Neuropsychological Laboratory, IRCCS Istituto Auxologico Italiano, \\ 20122 Milano, Italy
}

\begin{abstract}
Brain imaging studies in humans have shown the existence of a shared somatosensory representation in the primary somatosensory cortex (S1), putatively involved in understanding others' sensations (Keysers et al., 2010); however, the role of S1 in such a high-level process is still unknown. To ascertain the causal involvement of $S 1$, and its possible hemispheric lateralization, in encoding the affective valence of emotional scenes, depicting, or not, a tactile event, we gave to healthy participants a picture-based affective go/no-go task and low-frequency repetitive transcranial magnetic stimulation (rTMS). The dorsolateral prefrontal cortex (DLPFC) was chosen as control site. rTMS over the right, but not the left, S1 selectively increased the participants' latencies in the affective go/no-go task, but only when the affective state was conveyed by touch; intriguingly, this interfering effect was associated with the empathic ability to adopt the subjective perspective of others. The left, not the right, DLPFC is also involved in affective go/no-go performance, but regardless of the sight of touch, and independently of empathic abilities. This novel evidence demonstrates the crossmodal role of right $S 1$ in encoding the pleasant and aversive consequences of others' sensations evoked by touch.
\end{abstract}

\section{Introduction}

Touch has an emotional and communicative meaning, and therefore may play a peculiar role in social perception and empathy. Affective empathy consists in the affect produced in response to someone else's emotional state, a process that is facilitated by simulation or "mirroring" (Hein and Singer, 2008). This simulation theory of empathy predicts that the automatic and subconscious simulation of others' somatic states produces an embodied representation, which can aid the understanding of the feelings of the observed person (Preston and de Waal, 2002; Decety and Sommerville, 2003). In this perspective, the affect elicited by the sight of touch is driven by the emotion that may be conveyed by that touch (Hertenstein et al., 2006).

The involvement of a shared sensory dimension in empathic responses is supported by evidence showing that the mere observation of others' sensory and emotional states can produce a somatic activation in the observer: the observation and the firsthand experience of touch or pain, as well as the emotional recognition of facial expressions and self-generated emotions, activate primary (S1) and secondary somatosensory cortices (for review, see Keysers et al., 2010).

Received Sept. 21, 2012; revised Jan. 12, 2013; accepted Jan. 18, 2013.

Author contributions: N.B. and G.V. designed research; N.B., A.R., and S.C. performed research; N.B. and A.R. analyzed data; N.B., A.R., S.C., and G.V. wrote the paper.

We thank Viviana Spandri and Chiara Oprandi for assistance.

The authors declare no competing financial interests.

Correspondence should be addressed to Dr. Nadia Bolognini, Department of Psychology, University of MilanoBicocca, Piazza dell'Ateneo Nuovo 1, 20126, Milan, Italy. E-mail: nadia.bolognini@unimib.it.

DOI:10.1523/JNEUROSCI.4498-12.2013

Copyright $\odot 2013$ the authors $\quad 0270-6474 / 13 / 334201-05 \$ 15.00 / 0$
So far, the functional role of S1 in understanding others' sensations remains to be established. The consistent vicarious ("mirror-like") activation of S1 can be seen in two, not mutually exclusive, ways. It might reflect the unspecific coactivation of somatosensory representations by parietal and premotor neurons that are involved in understanding action consequences, by means of a feedback loop activating their associated somatosensory representations; alternatively, S1 might play a more specific causal role in coding the sensory consequences of the observed action, thereby informing the observer about the resulting sensations in others (Lamm et al., 2007).

A second unsolved issue is the possible hemispheric specialization of S1 in social interactions. There is evidence of a righthemispheric functional asymmetry for the social brain (Brancucci et al., 2009), emotion simulation (Adolphs et al., 2000), and self-other distinction (Ruby and Decety, 2004). Nevertheless, the neural bases of human resonance behavior are mainly located in the left hemisphere (Rizzolatti and Craighero, 2004; Minio-Paluello et al., 2006).

To assess the causal role of $\mathrm{S} 1$, and its possible hemispheric asymmetry, in coding the affective valence of social touch, we used low-frequency repetitive transcranial magnetic stimulation (rTMS) and a picture-based affective go/no-go task. The dorsolateral prefrontal cortex (DLPFC) was chosen as control site (Bermpohl et al., 2005). The advantage of this task, widely used in patients with affective disorders (Murphy et al., 1999), is to link explicitly emotional and cognitive functions, since response selection and inhibition must be guided by emotional content. The novelty of our approach was to include pictures depicting a physical contact, an essential feature for social behavior, for assessing the selectivity of S1 in affective categorization of seen touch. Fi- 


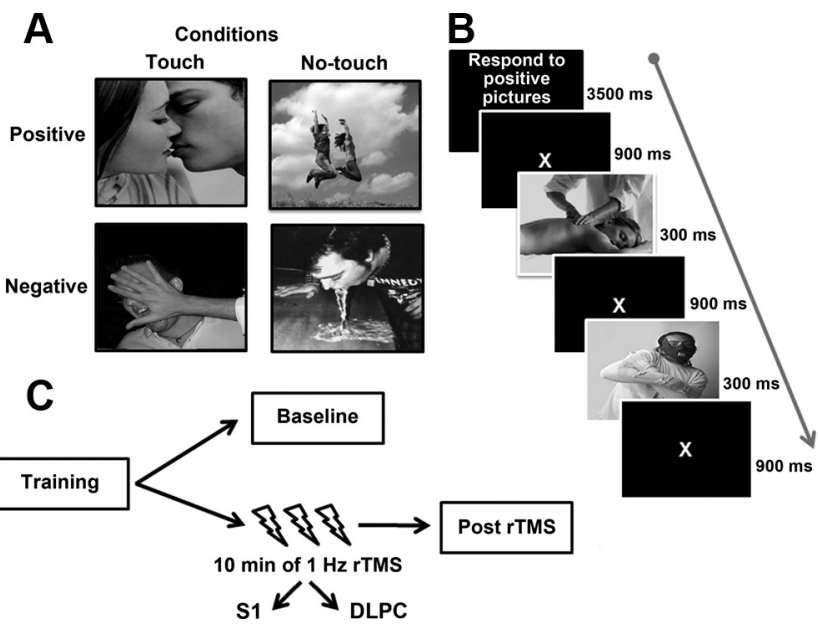

Figure 1. Conditions $(\boldsymbol{A})$ and sequence of events $(\boldsymbol{B})$ of the affective go/no-go task; experimental sessions (C).

nally, we explored whether activity in S1 may be related to differences in empathy.

\section{Materials and Methods}

Participants. Eighteen healthy, naive volunteers participated in Experiment 1 ( 2 males; 16 right-handed; mean age $\pm S D=22.6 \pm 3.5$ years), and 18 in Experiment 2 ( 3 males; 16 right-handed; age $=24.5 \pm 3.8$ years). Exclusion criteria included history of neurological and psychiatric disorders, and contraindications to rTMS (Rossi et al., 2009). The study, conducted in accordance with the Declaration of Helsinki, was approved by the local Ethical Committee. Written informed consent was obtained from participants.

Affective go/no-go task (adapted from Bermpohl et al., 2005). Color photographs $\left(18.4^{\circ} \times 18.4^{\circ}\right)$ were shown on a dark background (luminance $\left.=0.01 \mathrm{~cd} / \mathrm{m}^{2}\right)$. Stimuli belonged to two experimental conditions: the "Touch" condition, with emotionally evocative pictures depicting a physical contact, namely a person being touched by another person or by an object (e.g., caress to the arm, a syringe into the arm); and the "NoTouch" condition, with emotionally evocative pictures depicting a scene not involving a physical contact (e.g., a person having fun, an injured person) (Fig. 1A). Touch and No-Touch pictures were matched for: sex and number of characters, presence of facial or body emotions, and meaningful social interactions. The task comprised 32 pictures: 8 positive and 8 negative pictures for both Touch and No-Touch conditions. The reliable valence of these pictures was assessed through a preliminary experiment, where 22 healthy right-handed participants ( 3 males; age $=$ $22.5 \pm 3$ years) underwent the affective go/no-go task, as described below, which comprised 44 pictures ( 11 for each positive/negative condition). After the task, participants rated each picture on three $100 \mathrm{~mm}$ Visual Analog Scales (VAS), namely: (1) "Which is the valence of the picture?" (left end-point $=$ extremely negative/right end-point $=$ extremely positive); (2) "Which sensation is evoked by this picture?" (strong pain/great pleasure); (3) "How would you feel if you were in this situation?" (very bad/very well). In this way, we selected the 32 pictures with the highest reliable valence ratings, namely: positive Touch (mean accuracy $=93 \%, S D= \pm 4 \%$, mean VAS value $=88 \mathrm{~mm}, S D= \pm 5 \mathrm{~mm}$ ), positive No-Touch (accuracy $=91 \pm 4 \%$, VAS $=83 \pm 7 \mathrm{~mm}$ ), negative Touch (accuracy $=96 \pm 2 \%$, VAS $=9 \pm 8 \mathrm{~mm})$, and negative No-Touch $($ accuracy $=92 \pm 4 \%$, VAS $=12 \pm 10 \mathrm{~mm})$.

During the experimental task, the 32 pictures were presented twice, for a total of 64 trials (i.e., 16 positive and 16 negative trials for both Touch and No-Touch conditions), given in 4 blocks. Before each block, an instruction was given specifying either positive $[\mathrm{P}]$ or negative $[\mathrm{N}]$ pictures as targets. Instructions were presented in PNPN or NPNP order in every experimental session (see below), with half of participants starting with the $\mathrm{P}$ instruction. During the task, the target picture was presented for $300 \mathrm{~ms}$, followed by a blank window lasting $900 \mathrm{~ms}$ (Fig. 1B). Partic- ipants were instructed to respond as fast as possible to the target by pressing the space bar, while refraining from responding to distracters. The task lasted $\sim 10 \mathrm{~min}$. Sequence/timing of the stimuli, and responses' recording were under computer control (E-prime software, Psychology Software Tools Inc.).

TMS protocol. Low-frequency $(1 \mathrm{~Hz})$, off-line rTMS was delivered using a Magstim Super Rapid magnetic stimulator and a figure-of-eight coil $(\varnothing=70 \mathrm{~mm})$ for focal cortical stimulation. rTMS was delivered for $10 \mathrm{~min}$, with an intensity of $110 \%$ of the individual motor threshold at rest $(\mathrm{rMT}=$ minimum TMS intensity that elicited detectable motor twitches in the digits of the contralateral hand in 3 of 6 consecutive single TMS pulses) (Rossi et al., 2009). rMT was determined by stimulating the hand area of the right (Experiment 1) or left (Experiment 2) primary motor cortex. The mean rMT was $57 \pm 6 \%$ of the maximal output of the stimulator in Experiment 1, and $55 \pm 8 \%$ in Experiment 2.

In Experiment 1, we stimulated the right $\mathrm{S} 1$ in light of the efficacy of this stimulation for disrupting the visual perception of touch (Bolognini et al., 2011; Rossetti et al., 2012). The left DLPFC was chosen as active control site, given the left lateralization of the prefrontal contribution to affective go/no-go performance (Bermpohl et al., 2005). Experiment 2 explored hemispheric asymmetries of the $\mathrm{S} 1$ contribution to affective go/no-go performance by stimulating the left $\mathrm{S} 1$; now, the right DLPFC was the control site (Bermpohl et al., 2005).

The appropriate location for stimulating the $\mathrm{S} 1$ hand area was identified using a functional procedure: each participant performed a tactile detection task while receiving single TMS pulses (as described by Bolognini et al., 2011). During TMS, almost every subject reported paresthesia in the contralateral hand; 29 participants showed a deficit (omissions $=14.7 \%$ ) in detecting the contralateral touch.

The Talairach coordinates of the DLPFC $(x=-1+32, y=24, z=42)$, as reported in a previous fMRI study (Herrington et al., 2005), were localized with the SofTaxic Navigator system (Bolognini et al., 2011).

Throughout the rTMS sessions, the coil was fixed in position with the aid of an articulated mechanical arm.

\section{Experimental procedure}

Participants were comfortably seated in an armchair, in a quiet, dimly illuminated room, at a distance of $45 \mathrm{~cm}$ in front of a PC monitor (Samsung SyncMaster 1200NF). Both experiments comprised 4 sessions. The training session allowed participants to become familiarized with the task before the experiment (different pictures were presented, not included in the experimental task). There were three experimental sessions, counterbalanced across participants (ABC-BCA-CAB order) and separated by wash-out periods of at least $60 \mathrm{~min}$ : the baseline without rTMS; and two Post-rTMS sessions, in which the task was given after the delivery of rTMS over S1 or DLPFC (Fig. 1C). The entire procedure lasted $\sim 2 / 3 \mathrm{~h}$. In the baseline, half of the participants responded with the left index finger, and half with the right one, as a pilot study showed no difference in performance due to the hand used for responding ( $p>0.1)$; in the rTMS sessions, participants always responded with the hand ipsilateral to rTMS.

\section{Interpersonal Reactivity Index}

After each experiment, participants completed the Interpersonal Reactivity Index (IRI) (Davis, 1983), a 28-item self-report survey with four subscales: Perspective Taking (PT) and Fantasy (F), Empathic Concern (EC), and Personal Distress (PD). Cognitive empathy includes PT and F, affective empathy EC and PD. While PD taps self-oriented aspects of interpersonal reactivity, higher scores on PT, F, and EC are associated with other-oriented interpersonal activity.

\section{Statistical analysis}

Mean error rates and reaction times (RTs) were analyzed via a repeatedmeasures ANOVA with Experiment (right S1-left DLPFC, left S1-right DLPFC) as the between-subject factor, and Session (Baseline, S1-rTMS, DLPFC-rTMS), Condition (No-Touch, Touch), and Valence (Negative, Positive) as the within-subject factors. Post hoc comparisons were performed with the Bonferroni Test. RTs above or below 2 SD from the mean, as computed for each session, were discarded from the analysis; these data represented a minority of trials $(<10 \%)$. The effect size in the 


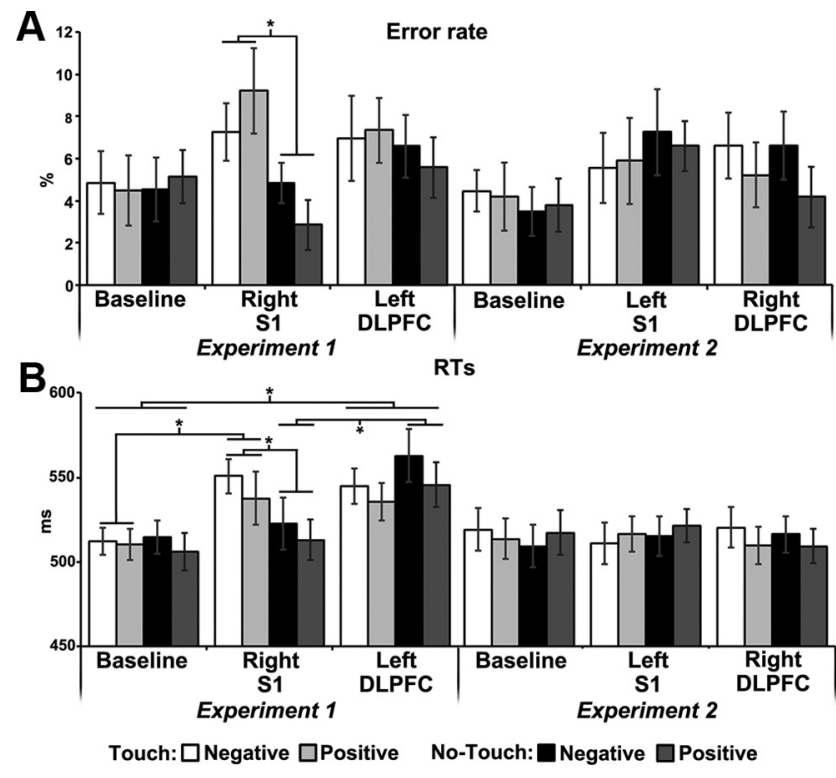

Figure 2. Error rate $(\boldsymbol{A})$ and RTs $(\boldsymbol{B})$ in Experiments 1 and 2. Error bars indicate SEM. Asterisks indicate significant difference.

ANOVAs was measured by calculating the partial Eta Squared $\left(\mathrm{p} \eta^{2}\right)$. Pearson's correlations were performed between the rTMS effect [namely, RT difference between the Baseline and rTMS sessions for Touch and No-Touch conditions (Post-rTMS minus Baseline: positive/negative values $=$ increased/decreased RTs by rTMS)], and the participants' scores on each IRI subscale. Correlation analyses were corrected for multiple comparisons using the Bonferroni method $(\alpha / 4=0.0125)$.

\section{Results}

The ANOVA performed on errors showed that the Experiment by Session by Condition interaction was significant $\left(F_{(2,68)}=\right.$ $\left.3.76, p=0.028, \mathrm{p} \eta^{2}=0.2\right)$. No other main effect or interaction was significant (all $p$ values $>0.1$ ). In the right S1-rTMS session, participants committed more errors in the Touch condition ( $8 \%$ ) than in the No-Touch condition $(4 \%, p=0.047)$ (Fig. $2 A)$; no other difference between conditions and sessions was significant (all $p$ values $>0.4$ ).

For RTs the main effect of Session was significant $\left(F_{(2,68)}=\right.$ $\left.7.15, p=0.0015, \mathrm{p} \eta^{2}=0.2\right)$; the Experiment by Session $\left(F_{(2,68)}=\right.$ 7.75, $\left.p<0.001, \mathrm{p} \eta^{2}=0.2\right)$ and the Session by Condition $\left(F_{(2,68)}=5.85, p=0.0045, \mathrm{p} \eta^{2}=0.2\right)$ interactions were significant. Crucially, the Experiment by Session by Condition interaction was significant $\left(F_{(2,68)}=12.29, p<0.0001, \mathrm{p} \eta^{2}=0.4\right)$, highlighting the selectivity of the rTMS effects (Fig. 2B). No other main effect or interaction was significant (all $p$ values $>0.1$ ). In Experiment 1 (rTMS delivered to right $\mathrm{S} 1$ and left DLPFC), in the No-Touch condition RTs increased after left DLPFC-rTMS (544.1 ms, $p<0.0001)$, compared with both Baseline (510.3 ms) and right S1-rTMS (517.8 ms); in the Touch condition, RTs increased after rTMS to both the DLPFC (540.2 ms) and the right S1 (544.1 ms), compared with Baseline (511.2 ms, $p<0.0001)$, with no difference between these rTMS sessions $(p=1)$. Touch and No-touch conditions differed after right S1-rTMS $(p<$ $0.0001)$, but neither during Baseline $(p=1)$ nor after left DLPFC-rTMS ( $p=0.4$ ). Instead, in Experiment 2 (rTMS delivered to left $\mathrm{S} 1$ and right DLPFC), there were no significant differences between conditions and sessions (all $p$ values $>0.1$ ).

A positive correlation was found between the Right-S1-rTMS effect in the Touch condition and the participants' score on the PT subscale $(r=0.58, p=0.0120)$ : the greater the individual PT

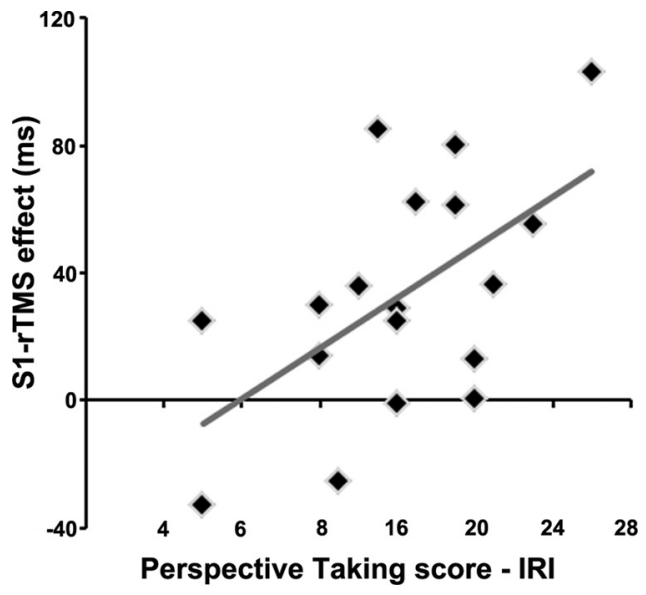

Figure 3. Correlation scatter plot for empathy subscale PT with the Right-S1-rTMS effect.

score, the greater the disruptive effect of right S1-rTMS on Touch stimuli (Fig. 3). Other correlations between the IRI subscales and the S1-rTMS and DLPFC-rTMS effects in the Touch and NoTouch conditions were not significant (all $p$ values $>0.2$ ).

\section{Discussion}

Four novel findings emerge from our study: (1) rTMS to S1 disrupts affective go/no-go task performance, but only in response to pictures where the emotional state is conveyed by a tactile event; (2) this effect is lateralized to the right hemisphere and 3) is associated with the empathy subscale Perspective Taking; and (4) the activity of the left DLPFC in affective go/no-go functions is independent of the sight of touch, and does not correlate with empathy.

This is the first demonstration that $\mathrm{S} 1$ is causally involved in encoding the valence of others' sensory states conveyed by a tactile event. In previous rTMS and neuropsychological experiments (Bolognini et al., 2011, 2012; Rossetti et al., 2012), we showed that visual information depicting a human touch induces a functionally relevant recruitment of (right) S1. Here, we further demonstrate not only that $S 1$ participates in the visual processing of touch, but also that $\mathrm{S} 1$ is essential to encode others' social or affective tactile experiences, independently from their positive or negative valence.

This is an intriguing finding since S1 has been considered a primary modality-specific area, involved in the processing of the lower-level sensory properties of touch (Penfield and Boldrey, 1937). Here, we show that $S 1$ is also sensitive to the visual aspects of touch processing over and above simple "bottom-up" somatosensory properties.

A dual role for touch serving both a discriminative and an affective role in human behavior has been described (McGlone et al., 2007). For instance, while S1 activation is found for processing physical aspects of the tactile stimulation, the orbitofrontal cortex, an area involved in emotional processing, is activated by both painful and pleasant touch, hence representing the emotional dimension of touch, namely rewarding and punishing (Francis et al., 1999; Rolls et al., 2003). With respect to the sight of touch, by decoupling the affective significance of a caress from its cutaneous sensory properties, a fMRI study (Gazzola et al., 2012) demonstrated that $\mathrm{S} 1$ can integrate visual and tactile information during the processing of interpersonal touch, and it is sensitive to the caressers' sex and to the perceived pleasantness of their sensual touch. Brain regions classically associated with affective processing of touch (insula, orbitofrontal and anterior cingulate 
cortices) are also activated by sensual caress, with only the orbitofrontal cortex being significantly modulated by visual sex (Gazzola et al., 2012). Ebisch et al. (2011) showed overlapping activation for the experience and observation of touch in S1 and S2, while an opposite activation pattern emerged in the insula for the experience (positive modulation) and the observation (negative modulation) of touch. In sum, the possibility may be entertained that brain regions involved in emotion contribute to the generation of knowledge about another person's affective state and draw on S1 for the construction of a shared representation of observed somatic feelings, via the process of simulation; this, in turn, would enable S1 to participate in the affective encoding of the seen touch.

Future studies shall assess whether the S1-rTMS effect generalizes to the categorization of different types of touch, in addition to that of affective valence shown here.

It is noteworthy that it is the right, not the left, S1 that can discriminate the valence of tactile events. This result is in line with neuropsychological evidence that damage to right somatosensory-related cortices, including S1, impairs recognition of basic emotions, making intensity judgments from photographs, and emotional concept retrieval (Adolphs et al., 1997, 2000; for TMS evidence see Pourtois et al., 2004, Pitcher et al., 2008). Neuroimaging studies also show a right S1 dominance for various social abilities. Empathy and perspective taking in complex social situations activate right S1 (Ruby and Decety, 2004). The simultaneous observation and execution of a finger movement activate somatosensory areas in the right hemisphere, a result interpreted as associated with the preservation of the sense of self (Iacoboni et al., 1999). Right S1 activity due to tactile stimulation is affected by personality traits (Schaefer et al., $2012 \mathrm{~b}$ ). On a broader perspective, there is a dominance of the right hemisphere in social behavior and empathy (Decety and Sommerville, 2003; Hein and Singer, 2008; Brancucci et al., 2009), such as understanding others' intention (Ortigue et al., 2009, 2010), agency attribution (Farrer and Frith, 2002; Lamm et al., 2007), and theory of mind (Happé et al., 1999; Gallagher et al., 2000; Saxe and Kanwisher, 2003). Finally, disorders of the sense of ownership of body parts are typically caused by right hemisphere lesions (Vallar and Ronchi, 2009).

Our study further shows that the right $\mathrm{S} 1$ is also engaged in social touch, being recruited for encoding the affective valence of others' somatic feelings. This right hemispheric lateralization could be the bridge linking a shared somatic representation, triggered by the sight of touch, with higher-order mentalizing processes involved in empathy. This view is supported by the significant association between the interfering effect of right S1rTMS and the empathy subscale Perspective Taking (PT), which assesses the ability to adopt the perspective of others. This correlation indicates that with increasing PT, individuals start to share the tactile consequences of seen touch, as also suggested by fMRI studies (Gazzola et al., 2006; Cheng et al., 2008; Schaefer et al., 2012a). Of note, the right S1 also shows a high specificity for first-person perspective in emotional contexts (Ruby and Decety, 2004). Overall, cognitive empathy skills, such as PT, seem to rely on the use of internal models of shared sensations to understand another person's situation (Gallese, 2007).

It is also noteworthy that, in addition to the local disruption within the stimulated area, TMS may affect neural activity in areas downstream to the stimulated site. Therefore, the present effects, while relying primarily on changes within S1, may also depend on effects on areas functionally connected to it (Bolognini and Ro, 2010).
Finally, we confirm the causal role of the left DLPFC in affective go/no-go performance, regardless of the sight of touch. The novel outcome is that left DLPFC activity does not correlate with empathy. So, the interfering effect of left DLPFC-rTMS is more linked to a deficit in more general cognitive functions, possibly executive processes and on-line manipulation of emotional information (Fuster, 1989; Bermpohl et al., 2005), rather than in empathic abilities. This, in turn, indicates that the neural basis of empathy may be dissociated from that of emotionally demanding cognitive judgments. Indeed, while the DLPFC is more relevant to executive aspects of cognition, orbitofrontal/ventromedial frontal areas play a prominent role in empathy (Preston and de Waal, 2002; Shamay-Tsoory et al., 2003; Salzman and Fusi, 2010; Rameson et al., 2012). Nonetheless, the prefrontal cortex may allow empathy to take place in a top-down manner: the cognitive functions of the DLPFC may interact with the vicarious activity of S1 when the encoding of others' feelings must be held in mind, and alternative interpretations considered.

In conclusion, the vicarious activity of the right $\mathrm{S} 1$ does not merely reflect an unspecific coactivation of somatosensory representations by the sight of touch, being instead functionally relevant for encoding pleasant and aversive consequences of seen tactile events, a function associated with empathy. In a social context, where affective states are evoked by touch, people can project themselves into the tactile situation faced by the other person, through the simulation mechanism supported by right $\mathrm{S} 1$.

\section{References}

Adolphs R, Cahill L, Schul R, Babinsky R (1997) Impaired declarative memory for emotional material following bilateral amygdala damage in humans. Learn Mem 4:291-300. CrossRef Medline

Adolphs R, Damasio H, Tranel D, Cooper G, Damasio AR (2000) A role for somatosensory cortices in the visual recognition of emotion as revealed by three-dimensional lesion mapping. J Neurosci 20:2683-2690. Medline

Bermpohl F, Fregni F, Boggio PS, Thut G, Northoff G, Otachi PT, Rigonatti SP, Marcolin MA, Pascual-Leone A (2005) Left prefrontal repetitive transcranial magnetic stimulation impairs performance in affective go/ no-go task. Neuroreport 16:615-619. CrossRef Medline

Bolognini N, Ro T (2010) Transcranial magnetic stimulation: disrupting neural activity to alter and assess brain function. J Neurosci 30:96479650. CrossRef Medline

Bolognini N, Rossetti A, Maravita A, Miniussi C (2011) Seeing touch in the somatosensory cortex: a TMS study of the visual perception of touch. Hum Brain Mapp 32:2103-2114.

Bolognini N, Olgiati E, Xaiz A, Posteraro L, Ferraro F, Maravita A (2012) Touch to see: neuropsychological evidence of a sensory mirror system for touch. Cereb Cortex 22:2055-2064. Medline

Brancucci A, Lucci G, Mazzatenta A, Tommasi L (2009) Asymmetries of the human social brain in the visual, auditory and chemical modalities. Philos Trans R Soc Lond B Biol Sci 364:895-914. CrossRef Medline

Cheng Y, Yang CY, Lin CP, Lee PL, Decety J (2008) The perception of pain in others suppresses somatosensory oscillations: a magnetoencephalography study. Neuroimage 40:1833-1840. CrossRef Medline

Davis MH (1983) Measuring individual differences in empathy: evidence for a multidimensional approach. J Pers Soc Psychol 44:113-126. CrossRef

Decety J, Sommerville JA (2003) Shared representations between self and other: a social cognitive neuroscience view. Trends Cogn Sci 7:527-533. CrossRef Medline

Ebisch SJ, Ferri F, Salone A, Perrucci MG, D’Amico L, Ferro FM, Romani GL, Gallese V (2011) Differential involvement of somatosensory and interoceptive cortices during the observation of affective touch. J Cogn Neurosci 23:1808-1822. Medline

Farrer C, Frith CD (2002) Experiencing oneself vs another person as being the cause of an action: the neural correlates of the experience of agency. Neuroimage 15:596-603. CrossRef Medline

Francis S, Rolls ET, Bowtell R, McGlone F, O’Doherty J, Browning A, Clare S, 
Smith E (1999) The representation of pleasant touch in the brain and its relationship with taste and olfactory areas. Neuroreport 10:453-459. CrossRef Medline

Fuster JM (1989) The prefrontal cortex. New York: Raven.

Gallagher HL, Happé F, Brunswick N, Fletcher PC, Frith U, Frith CD (2000) Reading the mind in diagrams and stories: an fMRI study of 'theory of mind' in verbal and nonverbal tasks. Neuropsychologia 38:11-21. CrossRef Medline

Gallese V (2007) Before and below 'theory of mind': embodied simulation and the neural correlates of social cognition. Philos Trans R Soc Lond B Biol Sci 362:659-669. CrossRef Medline

Gazzola V, Aziz-Zadeh L, Keysers C (2006) Empathy and the somatotopic auditory mirror system in humans. Curr Biol 16:1824-1829. CrossRef Medline

Gazzola V, Spezio ML, Etzel JA, Castelli F, Adolphs R, Keysers C (2012) Primary somatosensory cortex discriminates affective significance in social touch. Proc Natl Acad Sci U S A 109:E1657-1666. CrossRef Medline

Happé F, Brownell H, Winner E (1999) Acquired 'theory of mind' impairments following stroke. Cognition 70:211-240. CrossRef Medline

Hein G, Singer T (2008) I feel how you feel but not always: the empathic brain and its modulation. Curr Opin Neurobiol 18:153-158. CrossRef Medline

Herrington JD, Mohanty A, Koven NS, Fisher JE, Stewart JL, Banich MT, Webb AG, Miller GA, Heller W (2005) Emotion-modulated performance and activity in left dorsolateral prefrontal cortex. Emotion 5:200207. CrossRef Medline

Hertenstein MJ, Keltner D, App B, Bulleit BA, Jaskolka AR (2006) Touch communicates distinct emotions. Emotion 6:528-533. CrossRef Medline

Iacoboni M, Woods RP, Brass M, Bekkering H, Mazziotta JC, Rizzolatti G (1999) Cortical mechanisms of human imitation. Science 286:2526-2528. CrossRef Medline

Keysers C, Kaas JH, Gazzola V (2010) Somatosensation in social perception. Nat Rev Neurosci 11:417-428. CrossRef Medline

Lamm C, Nusbaum HC, Meltzoff AN, Decety J (2007) What are you feeling? Using functional magnetic resonance imaging to assess the modulation of sensory and affective responses during empathy for pain. PLoS One 2:e1292. CrossRef Medline

McGlone F, Vallbo AB, Olausson H, Loken L, Wessberg J (2007) Discriminative touch and emotional touch. Can J Exp Psychol 61:173-183. Medline

Minio-Paluello I, Avenanti A, Aglioti SM (2006) Left hemisphere dominance in reading the sensory qualities of others' pain? Soc Neurosci 1:320-333. CrossRef Medline

Murphy FC, Sahakian BJ, Rubinsztein JS, Michael A, Rogers RD, Robbins TW, Paykel ES (1999) Emotional bias and inhibitory control processes in mania and depression. Psychol Med 29:1307-1321. CrossRef Medline

Ortigue S, King D, Gazzaniga M, Miller M, Grafton S (2009) Right hemisphere dominance for understanding the intentions of others: evidence from a split-brain patient. BMJ Case Rep 2009.

Ortigue S, Sinigaglia C, Rizzolatti G, Grafton ST (2010) Understanding actions of others: the electrodynamics of the left and right hemispheres. A high-density EEG neuroimaging study. PLoS One 5:e12160. CrossRef Medline

Penfield W, Boldrey E (1937) Somatic motor and sensory representation of man as studied by electrical stimulation. Brain 60:389-443. CrossRef

Pitcher D, Garrido L, Walsh V, Duchaine BC (2008) Transcranial magnetic stimulation disrupts the perception and embodiment of facial expressions. J Neurosci 28:8929-8933. CrossRef Medline

Pourtois G, Sander D, Andres M, Grandjean D, Reveret L, Olivier E, Vuilleumier P (2004) Dissociable roles of the human somatosensory and superior temporal cortices for processing social face signals. Eur J Neurosci 20:3507-3515. CrossRef Medline

Preston SD, de Waal FB (2002) Empathy: Its ultimate and proximate bases. Behav Brain Sci 25:1-20; discussion 20-71. Medline

Rameson LT, Morelli SA, Lieberman MD (2012) The neural correlates of empathy: experience, automaticity, and prosocial behavior. J Cogn Neurosci 24:235-245. CrossRef Medline

Rizzolatti G, Craighero L (2004) The mirror-neuron system. Annu Rev Neurosci 27:169-192. CrossRef Medline

Rolls ET, O’Doherty J, Kringelbach ML, Francis S, Bowtell R, McGlone F (2003) Representations of pleasant and painful touch in the human orbitofrontal and cingulate cortices. Cereb Cortex 13:308-317. CrossRef Medline

Rossetti A, Miniussi C, Maravita A, Bolognini N (2012) Visual perception of bodily interactions in the primary somatosensory cortex. Eur J Neurosci 36:2317-2323.

Rossi S, Hallett M, Rossini PM, Pascual-Leone A, the Safety of TMS Consensus Group (2009) Safety, ethical considerations, and application guidelines for the use of transcranial magnetic stimulation in clinical practice and research. Clin Neurophysiol 120:2008-2039. CrossRef Medline

Ruby P, Decety J (2004) How would you feel versus how do you think she would feel? A neuroimaging study of perspective-taking with social emotions. J Cogn Neurosci 16:988-999. CrossRef Medline

Salzman CD, Fusi S (2010) Emotion, cognition, and mental state representation in amygdala and prefrontal cortex. Annu Rev Neurosci 33:173-202. CrossRef Medline

Saxe R, Kanwisher N (2003) People thinking about thinking people. The role of the temporo-parietal junction in "theory of mind." Neuroimage 19:1835-1842. CrossRef Medline

Schaefer M, Heinze HJ, Rotte M (2012a) Embodied empathy for tactile events: Interindividual differences and vicarious somatosensory responses during touch observation. Neuroimage 60:952-957. CrossRef Medline

Schaefer M, Heinze HJ, Rotte M (2012b) Touch and personality: extraversion predicts somatosensory brain response. Neuroimage 62:432-438. CrossRef Medline

Shamay-Tsoory SG, Tomer R, Berger BD, Aharon-Peretz J (2003) Characterization of empathy deficits following prefrontal brain damage: the role of the right ventromedial prefrontal cortex. J Cogn Neurosci 15:324-337. CrossRef Medline

Vallar G, Ronchi R (2009) Somatoparaphrenia: a body delusion. A review of the neuropsychological literature. Exp Brain Res 192:533-551. CrossRef Medline 